\title{
Nickel and GTP Modulate Helicobacter pylori UreG Structural Flexibility
}

\author{
Annalisa Pierro 1@, Emilien Etienne ${ }^{1}$, Guillaume Gerbaud ${ }^{1}$, Bruno Guigliarelli ${ }^{1}$, \\ Stefano Ciurli ${ }^{2}\left(\mathbb{D}\right.$, Valérie Belle ${ }^{1}$, Barbara Zambelli ${ }^{2, * \mathbb{D}}$ and Elisabetta Mileo ${ }^{1, *(\mathbb{D})}$ \\ 1 Aix Marseille Univ, CNRS, BIP, Bioénergétique et Ingénierie des Protéines, IMM, Marseille, France; \\ apierro@imm.cnrs.fr (A.P.); eetienne@imm.cnrs.fr (E.E.); ggerbaud@imm.cnrs.fr (G.G.); \\ guigliar@imm.cnrs.fr (B.G.); belle@imm.cnrs.fr (V.B.) \\ 2 Laboratory of Bioinorganic Chemistry, Department of Pharmacy and Biotechnology, University of Bologna, \\ 40127 Bologna, Italy; stefano.ciurli@unibo.it \\ * Correspondence: barbara.zambelli@unibo.it (B.Z.); emileo@imm.cnrs.fr (E.M.)
}

Received: 2 June 2020; Accepted: 10 July 2020; Published: 16 July 2020

\begin{abstract}
UreG is a P-loop GTP hydrolase involved in the maturation of nickel-containing urease, an essential enzyme found in plants, fungi, bacteria, and archaea. This protein couples the hydrolysis of GTP to the delivery of $\mathrm{Ni}$ (II) into the active site of apo-urease, interacting with other urease chaperones in a multi-protein complex necessary for enzyme activation. Whereas the conformation of Helicobacter pylori $(\mathrm{Hp})$ UreG was solved by crystallography when it is in complex with two other chaperones, in solution the protein was found in a disordered and flexible form, defining it as an intrinsically disordered enzyme and indicating that the well-folded structure found in the crystal state does not fully reflect the behavior of the protein in solution. Here, isothermal titration calorimetry and site-directed spin labeling coupled to electron paramagnetic spectroscopy were successfully combined to investigate $\mathrm{HpUreG}$ structural dynamics in solution and the effect of $\mathrm{Ni}$ (II) and GTP on protein mobility. The results demonstrate that, although the protein maintains a flexible behavior in the metal and nucleotide bound forms, concomitant addition of Ni(II) and GTP exerts a structural change through the crosstalk of different protein regions.
\end{abstract}

Keywords: intrinsically disordered proteins; EPR spectroscopy; isothermal titration calorimetry; protein-ligand interaction; site-directed spin labeling; protein structural dynamics

\section{Introduction}

The discovery of antimicrobials to defeat bacterial pathogens is among the most important medical advances of the last century. However, antimicrobial resistance (AMR) has impaired the efficacy of antibiotics against infections in the last decades, and is considered by the World Health Organization (WHO) as one of the most important threats to public health for the next future [1,2]. In 2017, WHO listed the twelve most important resistant bacteria at a global level for which there is urgent need for new therapies [3]. Ten of them produce the virulence factor urease, a nickel-enzyme that hydrolyzes urea to produce ammonia and carbamate, thus leading to $\mathrm{pH}$ increase [4]. This event provides a suitable environment for host colonization, both by producing a micro-environment compatible with bacterial growth and by supplying nitrogen sources. For example, Staphylococcus aureus urease activity determines biofilm formation and is required for bacterial persistence [5,6], while for Proteus mirabilis [7], Staphylococcus saprophyticus [8] and Ureaplasma ureolyticum [9] urease activity plays a central role for infection and urea stones formation in the urinary tract. Several of these pathogens are involved in bacterial infections of the respiratory apparatus. It is remarkable that half of patients who died of the recent CoViD19 epidemics in Wuhan (China) became co-infected with bacteria in the lungs 
and also required antibiotics [10]. Therefore, urease is an attractive target for the development of innovative antibacterial molecules, acting both as antibiotics, as well as preventive anti-virulence drugs or adjuvants for bacterial eradication.

One of the best-known pathogens that exploits the enzymatic activity of urease is the Gram-negative bacterium Helicobacter pylori, a widespread microbe, infecting the stomach of up to $50 \%$ and $80 \%$ of adults in industrialized and developing countries, respectively [11]. The infection causes chronic inflammation of the gastric mucosa, which can slowly progress to gastric ulcer and, through the premalignant stages of atrophic gastritis, to gastric adenocarcinoma or gastric mucosa-associated lymphoid tissue (MALT) lymphoma. In 1994, the WHO classified H. pylori as a class I carcinogen. The neutralization of $\mathrm{pH}$ driven by urease is required by $H$. pylori for the colonization of the gastric niche [12], while the generated ammonia and induced platelet activation also plays a critical role in the inflammatory response of the host and in the progress of the disease [13].

Bacterial ureases are generally heteropolymeric proteins with a quaternary structure $(\alpha \beta \gamma)_{3}[4,14,15]$. In the genus Helicobacter, the trimer is of the type $(\alpha \beta)_{3}$, with the $\beta$ subunits corresponding to the fused $\beta$ and $\gamma$ subunits normally found in other bacteria. The protein also presents a higher level of oligomerization with a $\left[(\alpha \beta)_{3}\right]_{4}$ quaternary structure [16]. Despite the different oligomeric organization, the structure of the known urease enzymes is fully conserved, and they present a substantially identical active site found in the $\alpha$ subunit. This site contains two Ni(II) ions bridged by the carboxylate group of a carbamylated lysine, essential to maintain the ions at the correct distance for catalysis, and by a hydroxide ion, the nucleophile in the hydrolysis reaction $[4,14,15]$.

Although previous studies identified several molecules that bind urease and inhibit it competitively or uncompetitively, none of them is generally used in therapy, due to their severe side effects or limited ability to pass the bacterial membrane [14,15]. Recently, an alternative strategy to design urease inhibitors has been proposed by targeting, instead of the enzyme, the process that delivers nickel ions into the enzyme active site, precluding enzyme maturation to the active Ni(II)-loaded urease [17]. This activation process is governed by the interplay of at least four accessory proteins, named UreD, UreE, UreF, and UreG, coded by genes belonging to a single operon together with the structural genes [4]. UreE acts as the metallo-chaperone of the system that delivers Ni(II) into urease [18], through tunnels that pass across a complex formed by UreD, UreF, and UreG, the last acting as a molecular chaperone that prepares urease to incorporate the metal ion [19]. Precluding urease maturation by blocking delivery of $\mathrm{Ni}(\mathrm{II})$ into its active site could thus represent a novel approach to enzyme inhibition.

The central player of the urease chaperone activation network is UreG, a GTPase that couples the energy obtained from GTP hydrolysis to urease maturation [20]. HpUreG interacts either with $H p U r e E$, forming a heterodimeric $H p \mathrm{UreG}_{2} \mathrm{E}_{2}$ complex [18], or with $H p \mathrm{UreF}$ and $H p \mathrm{UreD}$, forming a ternary $\mathrm{H} p \mathrm{UreG} \mathrm{F}_{2} \mathrm{~F}_{2} \mathrm{D}_{2}$ complex [21]. The multiplicity of partners of UreG is reflected in its folding flexibility: while the structure of the protein has been reported for the GDP-bound $H p U$ reG in the $H p \mathrm{UreG}_{2} \mathrm{~F}_{2} \mathrm{D}_{2}$ complex [21], and for the GMPPNP (guanylyl imidodiphosphate)-bound Klebsiella pneumonia (Kp) UreG [22], in solution, both $H p$ UreG and KpUreG feature high flexibility in solution, as shown by NMR spectroscopy, suggesting that the single conformation determined by X-ray crystallography does not reflect the flexible behavior of the protein in solution. This behavior is more generally observed in ${ }^{1} \mathrm{H},{ }^{15} \mathrm{~N}-\mathrm{HSQC}$ NMR spectra of a plethora of UreG homologues from bacteria, archaea, and plants, which show broad signals with limited spread in the ${ }^{1} \mathrm{H}$ dimension, indicating a backbone mobility in the intermediate exchange regime [23-26]. Native mass spectrometry and site-directed spin labeling coupled to electron paramagnetic resonance (SDSL-EPR) confirmed the presence of a heterogeneous conformational landscape for Sporosarcina pasteurii (Sp) UreG in the gas phase and in solution respectively, with at least two conformers with different degree of folding that coexist in equilibrium [27,28].

The selection of the binding partner is defined by the nucleotide bound state of the protein: GTP binding facilitates the formation of the $\mathrm{HpUreG} \mathrm{E}_{2}$ [29], while the GDP-bound form preferentially interacts in the $\mathrm{HpUreG}{ }_{2} \mathrm{~F}_{2} \mathrm{D}_{2}$ complex [21]. In addition, the concomitant presence of $\mathrm{Ni}(\mathrm{II})$ and GTP 
drives UreG dimerization in solution [21]. Ni(II) binds to a conserved Cys-Pro-His (CPH) motif, located on the protein interaction surface [30], while GTP binds on the opposite side of the protein [29].

A comparison of the crystal structure of the GMPPNP-bound KpUreG and the GDP-bound UreG in the $\mathrm{H} p \mathrm{UreG}_{2} \mathrm{~F}_{2} \mathrm{D}_{2}$ complex suggested that the presence of GTP drives an allosteric modulation of the $\mathrm{Ni}(\mathrm{II})$ binding site, which assumes a square planar geometry able to accommodate $\mathrm{Ni}$ (II) [22], suggesting that the two protein regions that bind $\mathrm{Ni}(\mathrm{II})$ and GTP/GDP communicate by allostery to drive the necessary conformational changes for UreG to function. However, such allosteric effect has not been proven in solution. The present study addresses this point, combining multiple biophysical approaches: SDSL-EPR, isothermal titration calorimetry (ITC), and static and dynamic light scattering (MALS-QELS).

In particular, we targeted three different regions of the protein with nitroxide-based spin labels and we performed both continuous wave and pulsed EPR spectroscopy in the presence of $\mathrm{Ni}(\mathrm{II})$ and GTP in order to determine their effect on the structural dynamics of HpUreG in solution, as well as to investigate the structural crosstalk of different protein regions occurring by flexibility modulation. The results obtained were complemented by ITC and MALS-QELS. Altogether, the results show that the concomitant addition of both $\mathrm{Ni}$ (II) and GTP induces a modification of the structure and mobility in two regions of the protein.

\section{Materials and Methods}

\subsection{Protein Expression and Purification}

The purification of $\mathrm{H} p \mathrm{UreG}$ and its mutants was performed using a protocol previously reported [20]. We improved the yield of the protein expression growing the cells into auto-induction medium containing glycerol $(5 \mathrm{~g} / \mathrm{L})$, glucose $(25 \mathrm{~g} / \mathrm{L})$, and lactose $(100 \mathrm{~g} / \mathrm{L})$, instead of LB combined with IPTG induction used in the previous work. The cells were grown $3 \mathrm{~h}$ at $37^{\circ} \mathrm{C}$ and $18 \mathrm{~h}$ at $28^{\circ} \mathrm{C}$. At the last step of purification, the proteins were in $20 \mathrm{mM}$ Tris $\mathrm{HCl} \mathrm{pH} 8$ buffer, containing $\mathrm{NaCl}$ $150 \mathrm{mM}$ and TCEP $1 \mathrm{mM}$. Protein concentration was estimated using absorbance at $280 \mathrm{~nm}$ and an extinction coefficient $\varepsilon_{280}=10,032 \mathrm{M}^{-1} \mathrm{~cm}^{-1}$.

\subsection{Isothermal Titration Calorimetry}

$\mathrm{Ni}(\mathrm{II})$ binding titrations of wild-type and C66A mutant $\mathrm{HpUreG}$ were performed at $25^{\circ} \mathrm{C}$ using a high-sensitivity VP-ITC microcalorimeter (MicroCal, Norcross, GA, USA). The protein and the metal ion salt $\left(\mathrm{NiSO}_{4}\right)$ were diluted to $40-80 \mu \mathrm{M}$ and $1.0 \mathrm{mM}$ respectively into a solution of $20 \mathrm{mM}$ Tris HCl $\mathrm{pH} 8$, containing $150 \mathrm{mM} \mathrm{NaCl}$ and $1 \mathrm{mM} \mathrm{TCEP}$, in the absence or in the presence of $150 \mu \mathrm{M}$ of the non-hydrolyzable GTP analogue, GTP $\gamma$ S. A reference cell was filled with deionized water. Before each experiment, the baseline stability was verified. An interval of $5 \mathrm{~min}$ was applied between the injections to allow the system to reach thermal equilibrium. Control experiments were conducted by titration of the metal ion solution into the buffer alone under identical conditions, and the heat of dilution was negligible. The solution containing the protein was loaded into a sample cell $(1.4093 \mathrm{~mL})$ and was titrated with $55 \times 5 \mu \mathrm{L}$ injections with the $\mathrm{Ni}(\mathrm{II})$ solution. The raw data were processed and fitted using Affinimeter software, with a nonlinear least-squares minimization algorithm to theoretical titration curves with stoichiometric binding schemes. For Ni(II) titration over apo-HpUreG and C66A mutant, restriction of the binding parameters had to be made by fixing the stoichiometry of 2 and 1 respectively, as the low affinity binding did not provide an optimal sigmoidicity of the curve with a clear inflection point. Attempts to fit with stoichiometry of 1,2,3, and 4 were made, and the chosen stoichiometry was the one that provided the best fit of the experimental data.

\subsection{HpUreG Mutants Design}

The cysteine mutations were introduced into $\mathrm{HpUreG}$ gene from Hp26695 strain urease operon (NCBI code NC000915) cloned into the pET15b expression vector (Novagen, Madison, WI, USA) in a previous work [20]. 
In order to relate and compare this work with previous studies, Cys66, wen mutated, was replaced by Alanine $[18,21,29]$. We decided to perform a Cysteine-Serine mutation for position 48 to preserve the surface charge of the protein, and a Cysteine-Alanine mutation in position 7 which is more buried in the crystal structure [22].

Mutants containing a single cysteine available for labeling were obtained by double mutation ("Site-directed mutagenesis" in Supplementary Materials Section S3). They were named as following: HpUreG-C7A-C48S: C66 ${ }^{\text {proxyl }}$; HpUreG-C7A-C66A: C48 ${ }^{\text {proxyl }}$; HpUreG-C66A-C48S: C7proxyl.

Variants containing two labeling sites and thus needing only one cysteine mutated were designed to perform distances measurements by DEER-EPR ("Site-directed mutagenesis" in Supplementary

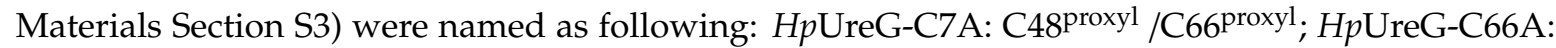
C7proxyl/C48 ${ }^{\text {proxyl }}$; HpUreG-C48S: C7proxyl/C66 ${ }^{\text {proxyl }}$.

\subsection{GTP Hydrolase Activity Assays}

HpUreG GTP hydrolyzing activity was measured by the SensoLyte ${ }^{\circledR}$ MG Phosphate Assay Kit (AnaSpec, Fremont, CA, USA), based on the colorimetric reaction involving malachite green reagent, molybdate, and orthophosphate.

Each sample was prepared mixing the reagents in order to obtain $20 \mu \mathrm{M}$ of protein, $400 \mu \mathrm{M}$ of GTP, and $2 \mathrm{mM}_{\text {of }} \mathrm{MgSO}_{4}$ in a final volume of $250 \mu \mathrm{L}$ of buffer. The reaction mixture (RM) was incubated for $2 \mathrm{~h}$ at $37^{\circ} \mathrm{C}$. Every $30 \mathrm{~min}, 40 \mu \mathrm{L}$ from the RM were incubated with $40 \mu \mathrm{L}$ of Malachite Green Mix for $10 \mathrm{~min}$ in a final volume of $300 \mu \mathrm{L}$ of buffer. After incubation, the absorbance at $600 \mathrm{~nm}$ was recorded. All the experiments were reproduced two times before estimating the Kcat values.

\subsection{Protein Labeling with Nitroxide Spin Label}

As $H p U$ reG variants are purified in presence of TCEP $1 \mathrm{mM}$, before labeling reaction, in order to avoid the reduction of the nitroxide spin label, the reductant removal is necessary. In general, a gel filtration using a PD-10 desalting column (GE Healthcare, Chicago, IL, USA) is sufficient. The labeling procedure is normally performed on $100 \mathrm{nmol}$ of protein in a reductant-free buffer (Tris $20 \mathrm{mM}$, $\mathrm{pH}=8, \mathrm{NaCl} 150 \mathrm{mM}$ ) in the presence of a 10-fold excess of nitroxide spin label, the maleimido-Proxyl (Sigma-Aldrich, St. Luis, MO, USA). A 20-fold excess was used for double Cys variants. The mixture is then incubated at $4{ }^{\circ} \mathrm{C}$, in the dark for $4 \mathrm{~h}$ under gentle stirring and continuous flow of argon. The excess of unbound label is removed by a second gel filtration with a PD-10 desalting column. The labeled protein is concentrated by using ultrafiltration (Vivaspin $5 \mathrm{kDa}$, Sartorius, Göttingen, Germany). The concentration of the labeled protein is evaluated by measuring the OD at $280 \mathrm{~nm}$. The labeling yield of mono-labeled variants analyzed was between $80 \%$ and $100 \%, 150-170 \%$ for double-labeled ones.

\subsection{EPR Spectroscopy}

X-band room temperature $(298 \mathrm{~K})$ continuous wave EPR measurements were recorded on an Elexsys500 Bruker spectrometer equipped with a Super High Q sensitivity resonator operating at X band $(9.9 \mathrm{GHz})$. The microwaves power was $10 \mathrm{~mW}$, the magnetic field modulation amplitude was $0.1 \mathrm{mT}$, the field sweep was $15 \mathrm{mT}$, the receiver gain was $60 \mathrm{~dB}$. All the samples were analyzed in quartz capillaries whose sensible volume was $40 \mu \mathrm{L}$.

The spin concentration was obtained by double integration of the EPR signal obtained under non-saturating conditions and the labeling yield was evaluated comparing the spin concentration with that one of a standard solution. For all variants, high labeling yields were obtained ranging from $80 \%$ to $100 \%$ for mono labeled samples and 150-170\% for double-labeled samples.

X-band cw EPR spectra at room temperature were recorded at $50 \mu \mathrm{M}$ of protein concentration in Tris $20 \mathrm{mM}, \mathrm{pH}=8, \mathrm{NaCl}=150 \mathrm{mM}$. When present, $\mathrm{Ni}(\mathrm{II})$ was $2.5 \mathrm{mM}\left(\mathrm{NiSO}_{4}\right), \mathrm{GTP} / \mathrm{GDP} 3 \mathrm{mM}$ (Sigma-Aldrich). 
The EPR spectra were simulated using SimLabel program [31], a Matlab graphical user interface using the Easyspin toolbox [32].

\subsection{DEER Measurements}

Inter-label distance distributions were obtained using the four-pulse DEER sequence [33]. Experiments were performed on a Bruker ELEXSYS E580 spectrometer at Q-band using the standard EN 5107D2 resonator. The system was equipped with an Oxford helium temperature regulation unit and the data were acquired at $60 \mathrm{~K}$. This temperature was optimized according to the relaxation times measured at variable temperatures in the range of $20-100 \mathrm{~K}$ with $10 \mathrm{~K}$ steps. All the measurements were performed on $20 \mu \mathrm{L}$ of sample loaded into quartz capillaries. DEER samples were flash frozen in liquid nitrogen. Distance distribution were extracted from DEER data through a Tikhonov regularization after baseline correction, using DeerAnalysis2019 software (http://www.epr.ethz.ch/software/index Jeschke G. 2011. DeerAnalysis. ETH, Zürich, Switzerland). Distance distributions measured were compared with the distance distributions predicted, analyzing the crystal of HpUreG (PDB 4HI0) [22] using the MMM software [34].

\section{Results and Discussion}

\subsection{Cys Variants Were Generated to Selectively Label Distinct Regions of HpUreG}

SDSL-EPR spectroscopy is a non-destructive technique that provides details on protein structure and flexibility over a wide-range of temperatures and timescales [35-38]. Proteins can be studied in their native environment, that is in membranes, in cellular extract and also inside cells [39]. SDSL-EPR involves the grafting of a paramagnetic label, generally a thiol-specific nitroxide, on the protein of interest and the determination of the dynamic properties of the attached nitroxide by continuous wave (CW)-EPR spectroscopy $[40,41]$. Changes in the nitroxide spectrum are thoroughly related to the mobility of the nitroxide side-chain and to the local backbone motion, which can thus be used to follow protein structural changes and to reveal interaction sites in complexes in solution and at room temperature [40,42-45]. Distance distributions between two spin labels can be measured by pulsed double electron-electron resonance (DEER) techniques relying on their dipole-dipole coupling [46,47]. Inter-label distance distributions can be investigated between 15 and $80 \AA$, but in specific experimental conditions, $160 \AA$ can be reached [48]. DEER experiments are usually carried out at cryogenic temperature $(60 \mathrm{~K})$, the low temperature being required to slow down the otherwise fast relaxation of nitroxide labels at higher temperature. As for all the other techniques requiring a freezing step, it is assumed that the conformational ensemble of the sample is captured.

Since most of the available nitroxide-based spin labels can specifically react with the thiol group of Cysteine, site-directed mutagenesis is often used to introduce Cys residues at specific locations in the primary structure of the protein of interest.

$\mathrm{H} p \mathrm{UreG}$ has three naturally occurring Cys, located in different regions of the protein (Figure $1 \mathrm{~A}$ ): (i) the conserved P-loop-motif, involved in GTP binding [20], accommodates Cys7; (ii) Helix 2, involved in GTP-dependent conformational changes, contains Cys48 [21]; (iii) the fully conserved CPH motif, involved in Ni(II) binding, includes Cys66 [20]. These positions allow, in principle, to monitor the mobility of three functionally important regions of the protein in solution. Consequently, six mutants containing one or two Cys residues were designed and labeled with the MA-Proxyl nitroxide to dissect the protein conformational landscape (Figure 1B): three double variants feature a unique position available for labeling ( $\mathrm{C}^{\text {prox }}$, corresponding to the Cys48Ser/Cys66Ala labeled mutant; $\mathrm{C}^{\text {prox }}$ corresponding to the Cys7Ala/Cys66Ala labeled mutant; $66^{\text {prox }}$, corresponding to the Cys7Ala/Cys48Ser labeled mutant), while three single variants possess two positions available for labeling for distance measurements $\left(\mathrm{C} 7^{\text {prox }} / \mathrm{C} 48^{\text {prox }}\right.$, corresponding to the Cys66Ala labeled mutant; $\mathrm{C} 7^{\text {prox }} / \mathrm{C} 66^{\text {prox }}$, corresponding to the Cys48Ser labeled mutant; ${\mathrm{C} 48^{\text {prox }}} / \mathrm{C} 66^{\text {prox }}$, corresponding to the Cys7Ala labeled mutant). Note that "WT ${ }^{\text {prox" }}$ corresponds to the wild-type protein (WT) labeled in 
the three naturally occurring Cys residues. The labeling reactions were checked by mass spectroscopy (see Supplementary Materials Figure S1). Any possible perturbation of the global structure and of the folding of $H p$ UreG mutations was excluded by controlling the global folding by circular dichroism (CD, see Figure S2). Similarly, the catalytic activity of $H p U r e G$ was monitored for the wild-type protein labeled in the three Cys positions (WT ${ }^{\text {prox }}$ ) (see Figure S1A), indicating no significant differences between the unlabeled and labeled proteins $\left(k_{\text {cat }}=0.027 \mathrm{~min}^{-1}\right.$ and $k_{\text {cat }}=0.023 \mathrm{~min}^{-1}$, respectively).
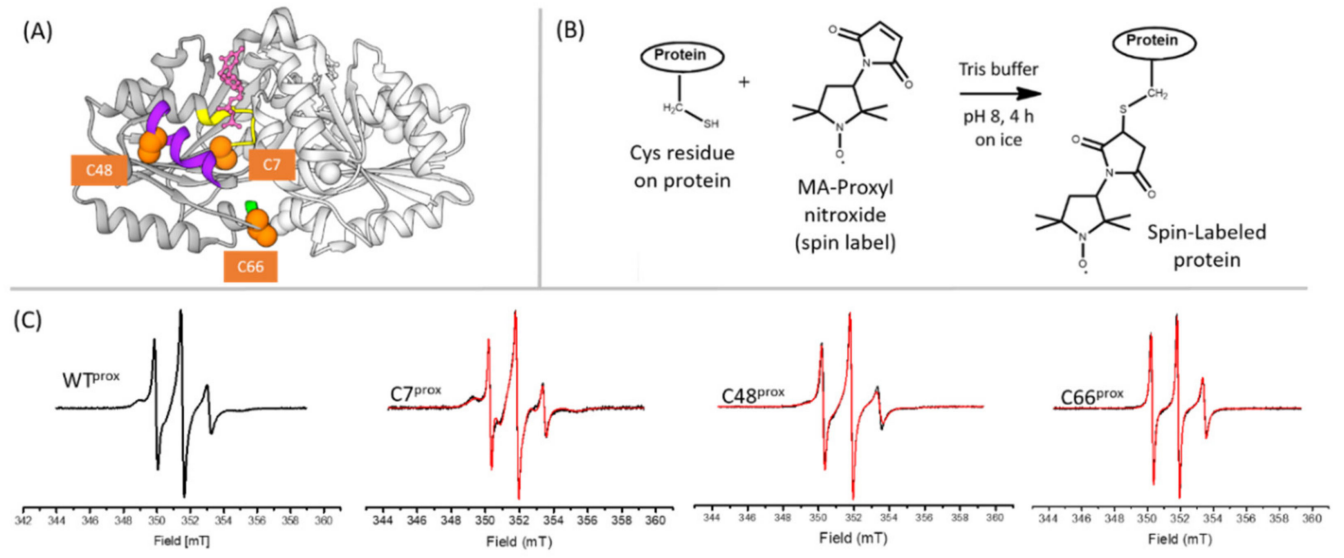

Figure 1. (A) $H p U r e G$ structure in the presence of GDP (pink) from the $H p U r e G_{2} \mathrm{~F}_{2} \mathrm{D}_{2}$ crystal (PDB $4 \mathrm{HI} 0$ ). The position of the three natural cysteine residues is highlighted in orange: Cys7 in the P-loop (yellow), Cys48 in the Helix 2 (purple), and Cys66 in the CPH Nickel binding site (green). (B) Labeling reaction scheme with MA-PROXYL nitroxide label. (C) Room temperature X-band EPR spectra of $50 \mu \mathrm{M}$ of wild-type $H p U r e G$ and its variants labeled with MA-PROXYL nitroxide in Tris buffer (black trace) and superimposed simulated spectra (red traces).

\subsection{The Thermodynamics of Ni(II) and GTP-Driven Dimerization of HpUreG Was Characterized}

Previous studies of $\mathrm{Ni}(\mathrm{II})$ binding to $\mathrm{Hp}$ UreG entailed the use of ITC, which showed that the isolated protein interacts with two $\mathrm{Ni}(\mathrm{II})$ ions per monomer with an exothermic reaction and a dissociation constant $K_{d}=10 \mu \mathrm{M}$ [20]. Ni(II) binding was also monitored using the gradual increase of absorption peak at $337 \mathrm{~nm}$, assigned to ligand-to-metal-charge transfer [29]. Differently from the ITC experiments, the latter approach did not detect any $\mathrm{Ni}$ (II) binding activity for the isolated protein, whereas metal binding occurred when GTP was added to the protein solution, under which condition $H p$ UreG was found to bind 0.5 equivalents of $\mathrm{Ni}(\mathrm{II})$ per protein monomer, with $K_{d}=0.33 \mu \mathrm{M}$, and to undergo dimerization upon metal binding [29].

Calorimetric titration of $\mathrm{Ni}(\mathrm{II})$ over a freshly purified $\mathrm{H} p \mathrm{UreG}$ sample, performed here for comparison with all other ITC data on $H p U r e G$ mutants and labeled forms described in the present study, confirmed the results previously obtained by ITC, showing negative peaks following each metal additions, indicative of an exothermic binding event (Figure 2A, left panel). The integrated heat data generated a binding isotherm with a single inflection point, and a mild slope (Figure 2A, right panel and Table 1). The fit of the obtained data, performed using the AFFINImeter software [49] and a model involving a single set of sites, showed that two Ni(II) ions bind per HpUreG monomer with similar affinity $\left(K_{d}=72 \mu \mathrm{M}\right)$, a favorable enthalpic contribution and a minor entropic impact (Table 1). Previously reported studies on $\mathrm{HpUreG}$ mutants indicated that at least one Ni(II) binding site is located on the CPH motif [20,29]. These observations outline two possible scenarios: (i) both Ni(II) ions bind to identical sites located in the region of $\mathrm{CPH}$, or (ii) one $\mathrm{Ni}$ (II) ion binds to the CPH motif while the second binds to the different site; in the latter case, a possibility is represented by the $\mathrm{Mg}$ (II) binding sites close to the GTP binding pocket, as previously suggested [29]. The difference in Ni(II) affinity thus measured for HpUreG $(72 \mu \mathrm{M})$ with the previously reported value obtained by ITC $(10 \mu \mathrm{M})$ [20] is likely due to the experimental conditions: for the ITC titrations, the relatively weak metal-protein affinity caused the value of the c-parameter, namely the product of the concentration of the protein in 
the cell by the binding constant, to be close to its lowest acceptable limit [20], rendering the calculated affinity constants less accurate.
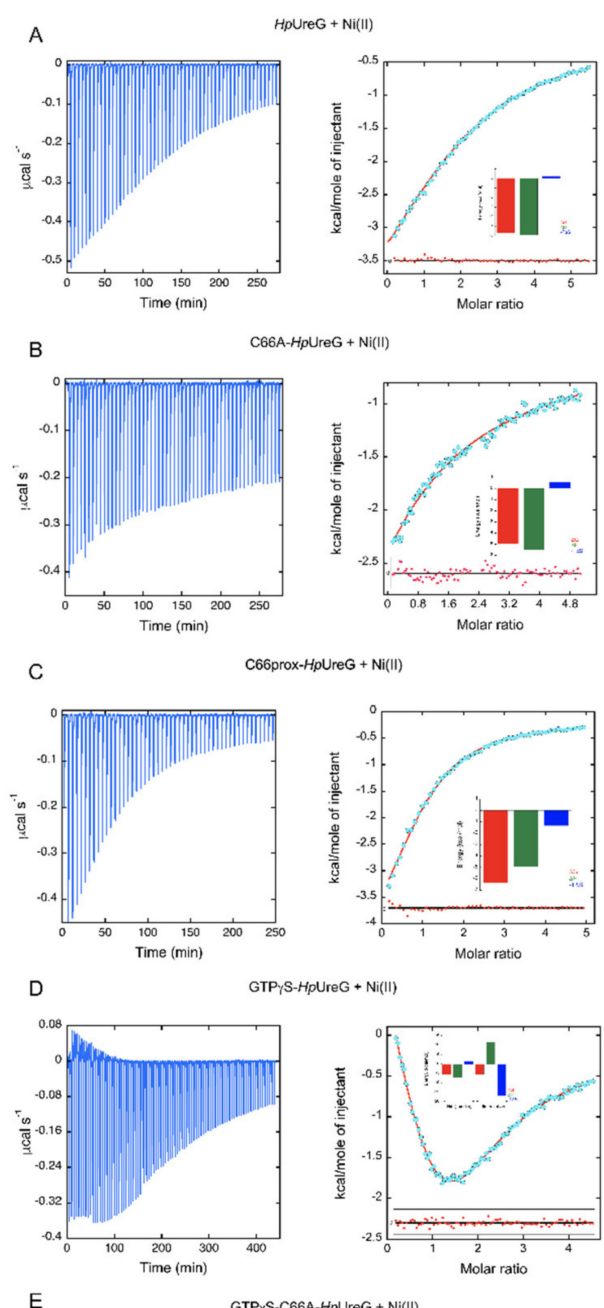

E

GTPYS-C66A-HpUreG + Ni(II)
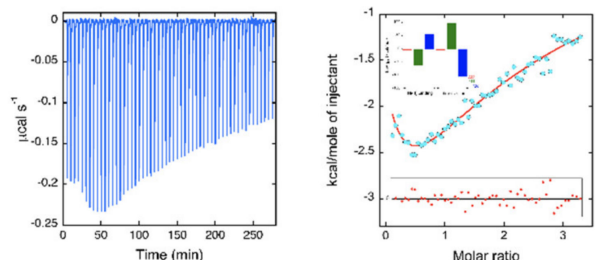

$\mathrm{F}$

GTPYS-C66prox-HPUreG + Ni(II)
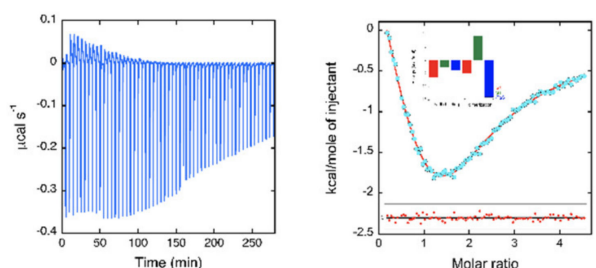

Figure 2. Isothermal Titration Calorimetry (ITC) of Ni(II) over $\mathrm{HpUreG}$ and its variants in the presence and in the absence of GTP $\gamma S$ in the sample cell. The panels on the left report the heat flow response for the injections of the metal ion over the protein solutions. The panels on the right show the respective integrated heat data (blue circles) and their best fit obtained using a single set of binding sites (A-C) or a model involving protein dimerization upon metal binding (D-F); the insets show the binding signatures $(\Delta \mathrm{G}, \Delta \mathrm{H},-\Delta \mathrm{T}, \Delta \mathrm{S})$ associated to each curve; the bottom plots show the residuals of the fitting procedure. 
Table 1. Thermodynamic parameters of Ni(II) titrations over HpUreG and its variants, in the absence and in the presence of GTP $\gamma \mathrm{S}$.

\begin{tabular}{|c|c|c|c|c|c|}
\hline Sample in the ITC Cell & $\mathbf{N}$ & $K_{a}\left(M^{-1}\right)$ & $K_{d}(\mu M)$ & $\begin{array}{c}\Delta \mathrm{H} \\
\left(\mathrm{kcal} \mathrm{mol}^{-1}\right)\end{array}$ & 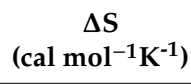 \\
\hline HpUreG & 2 & $1.38 \pm 0.02 \times 10^{4}$ & $72 \pm 1$ & $-5.90 \pm 0.06$ & -0.86 \\
\hline C66A-HpUreG & 1 & $4.23 \pm 0.02 \times 10^{3}$ & $236 \pm 1$ & $-5.52 \pm 0.01$ & -1.93 \\
\hline $\mathrm{WT}^{\text {prox }}-\mathrm{H} p \mathrm{UreG}$ & 1 & $4.33 \pm 0.04 \times 104$ & $23.0 \pm 0.3$ & $-4.99 \pm 0.02$ & 4.47 \\
\hline$H p$ UreG-GTP $\gamma \mathrm{S}$ & $\begin{array}{l}\text { HpUreG-Ni } \\
\text { HpUreG }_{2}-\mathrm{Ni}\end{array}$ & $\begin{array}{l}3.45 \pm 0.02 \times 10^{4} \\
1.40 \pm 0.04 \times 10^{4}\end{array}$ & $\begin{array}{c}30.0 \pm 0.2 \\
71 \pm 2\end{array}$ & $\begin{array}{l}-7.14 \pm 0.06 \\
+11.2 \pm 0.3\end{array}$ & $\begin{array}{l}-4.99 \\
+56.77\end{array}$ \\
\hline C66AH $p$ UreG-GTP $\gamma \mathrm{S}$ & $\begin{array}{l}\text { C66AHpUreG-Ni } \\
\text { C66AHpUreG }_{2}-\mathrm{Ni}\end{array}$ & $\begin{array}{l}6.1 \pm 0.8 \times 10^{3} \\
4.5 \pm 0.7 \times 10^{4}\end{array}$ & $\begin{array}{c}160 \pm 20 \\
22 \pm 3\end{array}$ & $\begin{array}{l}-61 \pm 7 \\
+99 \pm 9\end{array}$ & $\begin{array}{l}-187 \\
+353\end{array}$ \\
\hline $\mathrm{WT}^{\text {prox }}-\mathrm{H} p \mathrm{UreG}-\mathrm{GTP} \gamma \mathrm{S}$ & $\begin{array}{l}\text { WT }^{\text {Prox }}-\mathrm{HpUreG-Ni} \\
\mathrm{WT}^{\text {Prox }}-\mathrm{HpUreG}_{2}-\mathrm{Ni}\end{array}$ & $\begin{array}{c}4.20 \pm 0.04 \times 10^{4} \\
3.8 \pm 0.3 \times 10^{3}\end{array}$ & $\begin{array}{c}23.8 \pm 0.2 \\
260 \pm 20\end{array}$ & $\begin{aligned}-2.63 & \pm 0.03 \\
+9.1 & \pm 0.5\end{aligned}$ & $\begin{array}{l}+12.3 \\
+46.8\end{array}$ \\
\hline
\end{tabular}

Mutation of the $\mathrm{Ni}(\mathrm{II})$ binding residue Cys66 to Ala was previously reported to fully abolish $\mathrm{Ni}(\mathrm{II})$ binding capability of the protein [29]. Here, the ITC titration instead revealed that the Cys66Ala-HpUreG mutant is still able to bind one $\mathrm{Ni}$ (II) ion per protein monomer, with an exothermic reaction (Figure 2B, left panel) and one order of magnitude lower affinity $(K d=236 \mu \mathrm{M})$, with substantially invariant enthalpic and entropic contributions (Figure 2B, right panel and Table 1). This observation suggests that the two $\mathrm{Ni}(\mathrm{II})$ binding sites per monomer, observed in wild-type $\mathrm{HpUreG}$, are distinct, with one site, involving Cys66 in the CPH motif, that is abrogated by the Cys66-to-Ala mutation, while the second is maintained. The decreased affinity for the latter site $\left(K_{d}=236 \mu \mathrm{M}\right.$ vs. $72 \mu \mathrm{M}$ for the mutated and WT protein, respectively) suggests the presence of cooperativity between the two metal binding sites. The triply labeled WT ${ }^{\text {prox }}$, while showing the same exothermic effect (Figure 2C, left panel) and the same stoichiometry as the Cys66Ala mutant, features an higher affinity for $\mathrm{Ni}(\mathrm{II})\left(K_{d}=23 \mu \mathrm{M}\right)$, a similar enthalpic value and positive entropic contribution (right panel of Figure $2 \mathrm{C}$ and Table 1 ), as compared to the Cys66Ala mutant $\left(K_{d}=236 \mu \mathrm{M}\right)$, indicating that the Cys labeling with the nitroxide moiety still abolishes one of the two Ni(II) binding sites observed for the unlabeled WT protein, but, differently from the Cys66Ala mutation, maintains a similar affinity for the second $\mathrm{Ni}(\mathrm{II})$ binding event, supporting the idea of cooperativity between the two Ni-binding sites in the WT protein.

$\mathrm{Ni}(\mathrm{II})$ - and GTP $\gamma \mathrm{S}$-driven dimerization [29] was verified under the ITC experimental conditions using size-exclusion chromatography coupled to multi-angle light scattering (SEC-MALS, Figure S3). The obtained results confirmed that $H p$ UreG undergoes dimerization when both Ni(II) and GTP $\gamma \mathrm{S}$, a non-hydrolyzable GTP analogue, are added to the protein solution, while it remains monomeric in the presence of either $\mathrm{Ni}(\mathrm{II})$ or GTP $\gamma \mathrm{S}$ alone.

The thermodynamics of $\mathrm{Ni}(\mathrm{II})$ and GTP $\gamma \mathrm{S}$-driven protein dimerization was therefore addressed using ITC. Ni(II) ions were titrated over HpUreG in the presence of GTP $\gamma \mathrm{S}$ in the sample cell. Negative peaks followed each injection of $\mathrm{Ni}$ (II) into the protein solution, indicating the occurrence of an exothermic reaction (Figure 2D, left panel). The observation of a slower endothermic effect following each injection, which terminates when one equivalent of metal is added to the protein solution, suggested the existence of another process, in addition to metal binding, similarly to what had been previously observed for the $\mathrm{Ni}(\mathrm{II})$-sensor $H p \mathrm{NikR}$ [50]. This type of ITC trace can be interpreted either as a conformational modification or as a change in the oligomerization state of the protein. As dimerization was demonstrated by light scattering experiments (Figure S3) [29], and the shape of the binding isotherm clearly indicated two inflection points suggestive of two reactions occurring upon metal titration, the data were analyzed using a model involving two successive equilibria, with protein dimerization following the binding of one $\mathrm{Ni}$ (II) per protein dimer (Scheme 1). 


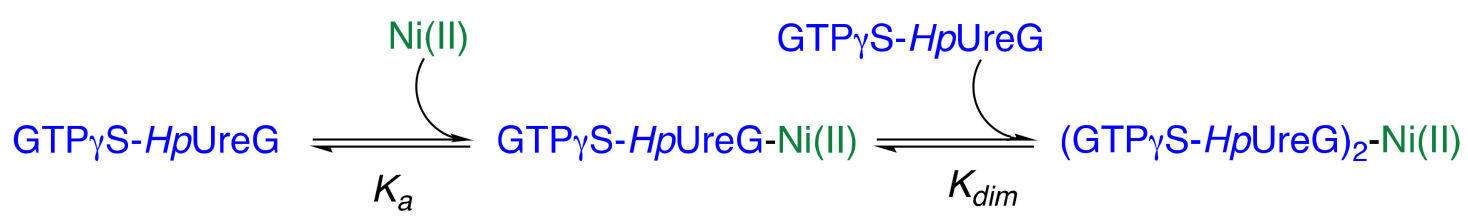

Scheme 1. Equation defining the model used to fit the ITC data for Ni(II) titration over GTP $\gamma$ S-HpUreG, involving metal binding and protein dimerization.

Fitting of the binding isotherm (Figure 2D, right panel and Table 1) indicated that one $\mathrm{Ni}(\mathrm{II})$ ion binds per protein monomer in the presence of GTP $\gamma \mathrm{S}$, with a dissociation constant two times smaller than that reported for the apo-protein $\left(K_{d}=30 \mu \mathrm{M}\right)$, while protein dimerization occurs with $K_{d i m}=$ $71 \mu \mathrm{M}$. In this case, $\mathrm{Ni}(\mathrm{II})$ binding occurs with thermodynamic parameters similar to the ones observed for the apo-protein, with favorable enthalpy and a negative entropic contribution (Table 1). On the other hand, dimerization is an entropy-driven endothermic process as expected (Table 1). The entire two-step process is characterized by a global dissociation constant of $K_{d}=2 \mathrm{nM}$. This value should be compared with that obtained by absorbance spectroscopy for $\mathrm{Ni}$ (II) binding to $\mathrm{H} p \mathrm{UreG}$ in the presence of GTP $\gamma \mathrm{S}\left(K_{d}=0.33 \mu \mathrm{M}\right)$ [29]. The difference between these two values could be attributed to the different $\mathrm{pH}$ at which the measurements were carried out in the present (8.0) and in the previous (7.2) work. The apparent decrease in affinity at lower $\mathrm{pH}$ is consistent with a proton dissociation event occurring upon metal binding, which possibly involves a cysteine residue (Cys66 in this case), as previously observed in the case of the nickel-dependent transcription factor $H p N i k R$ [50].

$\mathrm{Ni}(\mathrm{II})$ titration over the Cys66Ala mutant in the presence of GTP $\gamma \mathrm{S}$ produced negative peaks indicative of an exothermic binding of $\mathrm{Ni}(\mathrm{II})$, but no endothermic effect was visible (Figure 2E, left panel), suggesting that a dimerization is either not occurring in this case or is occurring with much lower affinity, resulting in the absence of detectable endothermic heat. The binding isotherm (Figure 2E, right panel) showed two inflection points, and the same model reported in Scheme 1 was used to treat the data. According to the fit, the first event of $\mathrm{Ni}(\mathrm{II})$ binding occurs with one order of magnitude lower affinity $\left(K_{d}=160 \mu \mathrm{M}\right)$ as observed for the Cys66Ala mutant in the absence of GTP $\gamma \mathrm{S}$ (Figure 2A), while the second equilibrium shows a similar constant $\left(K_{d}=22 \mu \mathrm{M}\right)$. In this case, the thermodynamic parameters associated to the metal binding step and to the second process (Table 1) are unusually high compared to all other similar data in this study, suggesting that additional phenomena other than metal binding and dimerization are occurring in the case of this mutant. It is worth noticing that, during sample manipulation, the Cys66Ala mutant was prone to precipitation, especially in the presence of $\mathrm{Ni}(\mathrm{II})$, suggesting that at least part of the protein sample undergoes aggregation upon $\mathrm{Ni}(\mathrm{II})$ titration, which might be the second process evidenced in the binding isotherm.

$\mathrm{Ni}(\mathrm{II})$ titration over the triply labeled WT ${ }^{\text {prox }}$ protein in the presence of GTP $\gamma \mathrm{S}$ (Figure 2F, left panel) produced a bipartite binding isotherm (Figure 2F, right panel), whose analysis, performed according to Scheme 1, indicated that $\mathrm{Ni}$ (II) ion binding to the protein dimer occurs with an affinity similar to the wild type protein $\left(K_{d}=23.8 \mu \mathrm{M}\right)$, and favorable enthalpic and entropic contributions (Table 1 ). On the other hand, the second process is less favorable for WT ${ }^{\text {prox }}$, occurring with a lower equilibrium constant $\left(K_{d}=260 \mu \mathrm{M}\right)$ as compared to the dimerization of the WT protein. If the second process also involves dimerization for $\mathrm{WT}^{\text {prox }}$ (as suggested by the values of $\Delta H$ and $\Delta S$, see Table 1 ), this decreased value could be due to a steric effect of the nitroxide label.

\subsection{HpUreG Shows Distinct Flexibility in Different Protein Regions}

The EPR spectrum of WT HpUreG labeled with MA-Proxyl nitroxide (WT ${ }^{\text {Prox }}$, Figure 1C) arises from the contribution of spin labels simultaneously grafted onto the three Cys residues. To separately dissect the conformational flexibility of different regions of $H p U r e G$, the EPR spectrum of the nitroxide-labeled $\mathrm{H} p \mathrm{UreG}$ variants that contain a single labeled cysteine (C7prox, $\mathrm{C} 48^{\text {prox }}$, and $\mathrm{C}_{6}{ }^{\text {prox }}$ ) were performed in solution and at room temperature (Figure 1C). Qualitatively, when the nitroxide mobility decreases, a broadening of the EPR spectral line shape is expected. For the single 
labelled $H p$ UreG variants, the spectra show different mobility: the line shape becomes sharper going

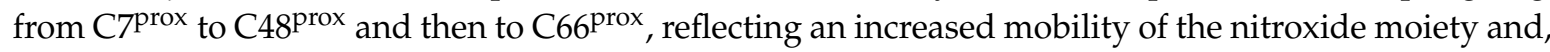
consequently, of the protein structural motif to which the label is attached (Figure 1C). A quantitative view of the nitroxide dynamics in terms of the rotational correlation time $\left(\tau_{c}\right)$ and of the magnetic parameters ( $g$-factor and hyperfine A-tensors) was obtained by simulating the EPR spectra with SimLabel [31] (a MatLab graphical user interface using the Easyspin toolbox [32]) (see Table 2 and Supplementary Materials Section S2). As very often found in SDSL-EPR studies [27], the spectra of $H p U r e G$ could be simulated by two components, which represent populations of spin labels characterized by different dynamics. These populations can be related either to rotameric states of the spin label or to structural sub-states of the protein in conformational equilibrium. In the case of $H p \mathrm{UreG}$, the large difference in the dynamics of the two components (see $\tau_{\mathrm{c}}$ in Table 2), generally not observed for rotamers [51], suggests that they reflect distinct protein conformational states [51,52]. This conclusion is consistent with similar phenomena reported for SpUreG [27], and is further supported by the observation that the HpUreG EPR spectrum of $C 66^{\text {prox }}$ is modified by the addition of glycerol, a protective osmolyte: in this case, the spectrum can be simulated by increasing the contribution of the slower component, which changes from 44 to $70 \%$ (Table 2 and Figure S4). Protective osmolytes are indeed known to modify the conformational equilibria among different conformational states of the protein [53], stabilizing the protein structure toward a more folded conformation [52].

Table 2. Electron Paramagnetic Resonance (EPR) spectra simulation parameters: rotational correlation times $\left(\tau_{\mathrm{c}}\right.$ in $\mathrm{ns}$ ) and proportion (\%) of the simulated multi-components of the spectra of HpUreG variants under various conditions.

\begin{tabular}{|c|c|c|c|c|c|c|c|}
\hline \multirow[b]{2}{*}{ Labeled Site } & \multirow[b]{2}{*}{ Component } & \multicolumn{2}{|c|}{ Apo-Form } & \multicolumn{2}{|c|}{ +Ni(II) } & \multicolumn{2}{|c|}{$+\mathrm{Ni}(\mathrm{II})$ and GTP } \\
\hline & & Weight \% & $\tau c(n s)$ & Weight \% & $\tau c(n s)$ & Weight \% & $\tau c(n s)$ \\
\hline \multirow{2}{*}{ C66 prox } & Fast & 56 & 0.6 & 34 & 0.6 & 28 & 0.7 \\
\hline & Slow & 44 & 2.4 & 66 & 2.4 & 72 & 3.4 \\
\hline \multirow{2}{*}{$\begin{array}{c}\text { C66 prox } \\
+g l y 30 \%\end{array}$} & Fast & 30 & 0.6 & 22 & 0.6 & 19 & 0.8 \\
\hline & Slow/Rigid * & 70 & 2.4 & 78 & 2.4 & $81^{*}$ & $4.4^{*}$ \\
\hline \multirow{2}{*}{$\mathrm{C} 48^{\text {prox }}$} & Fast & 37 & 0.6 & 39 & 0.6 & 21 & 0.6 \\
\hline & Rigid & 63 & 4.9 & 61 & 4.9 & 79 & 4.9 \\
\hline \multirow{2}{*}{ C7prox } & Fast & 20 & 0.3 & 15 & 0.3 & 14 & 0.3 \\
\hline & Rigid & 80 & 6.1 & 85 & 6.1 & 86 & 6.1 \\
\hline
\end{tabular}

The symbol (*) indicates the "rigid" component.

Note that, in the following paragraphs, we named "fast" all spectral components characterized by $\tau_{\mathrm{c}}$ values included between $0.3-0.7 \mathrm{~ns}$, "slow" those characterized by $\tau_{\mathrm{c}}$ values included between $0.7-4.0 \mathrm{~ns}$, and "rigid" components characterized by $\tau_{\mathrm{c}}$ values included between $4.0-6.2 \mathrm{~ns}$. The sharpest EPR line shape is observed for the nitroxide grafted to Cys66. This spectrum is constituted by two components having almost the same proportion, one with $\tau_{\mathrm{c}}=0.6 \mathrm{~ns}$ ("fast") and the other with $\tau_{\mathrm{c}}=2.4$ ns ("slow") (Table 2 and Figure 3). The fact that the "fast" component shows a mobility close to that normally observed for a spin label attached to loops or intrinsically disordered protein fragments $[27,44,54]$ demonstrates that this region is highly flexible. This dynamic behaviour is similar to that observed for the SpUreG orthologue containing the nitroxide label grafted onto the corresponding cysteine residue, which features two conformers with similar correlation times $\left(\tau_{\mathrm{c}}\right.$ "fast" $=0.3 \mathrm{~ns}$ and $\tau_{\mathrm{c}}$ "slow" $=3.6 \mathrm{~ns}$ ) (see Figure S5) [27].

Similarly, two components with different degrees of flexibility and comparable relative abundance are observed for $\mathrm{C} 48^{\text {prox }}$ : one features a "fast" behavior $\left(\tau_{\mathrm{c}}=0.6 \mathrm{~ns}\right)$, while the other ("rigid") is consistent with a less flexible dynamic $\left(\tau_{\mathrm{c}}=4.9 \mathrm{~ns}\right)$ (Table 2 and Figure 3$)$. On the other hand, a "rigid" component $\left(\tau_{\mathrm{c}}=6.1 \mathrm{~ns}\right)$ is dominant $(80 \%)$ in the case of $\mathrm{C} 7^{\text {prox }}$, for which a less abundant component $(20 \%)$ shows a "fast" behavior $\left(\tau_{\mathrm{c}}=0.3 \mathrm{~ns}\right.$ ) (Table 2 and Figure 3 ). The latter case can be explained by 
considering that the nitroxide moiety resides in a well-structured region or in a buried site. The high yield of labeling reached for this site (80-100\%, Figure S1) suggests that Cys7 is accessible, so the observed rigid behavior is indicative of the presence of a highly rigid protein segment.

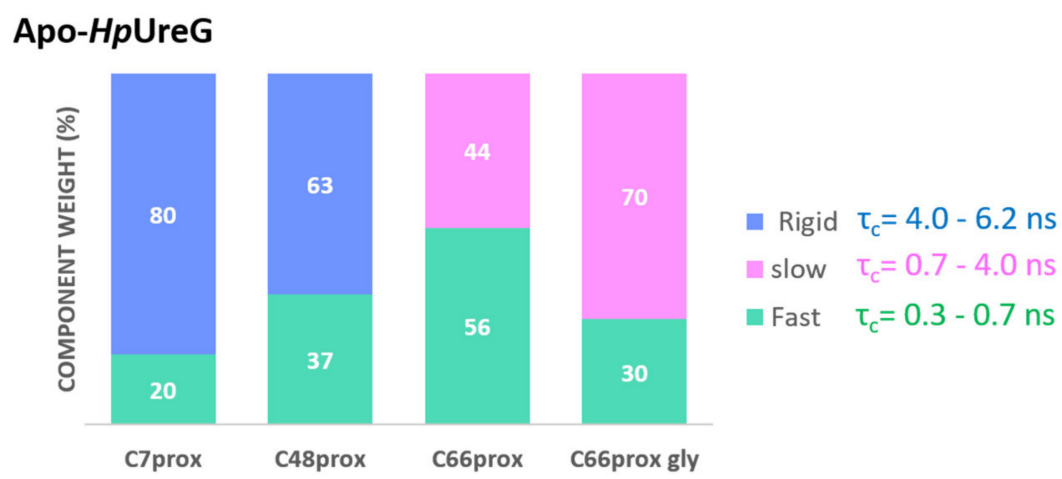

Ni(II), GTP-HpUreG

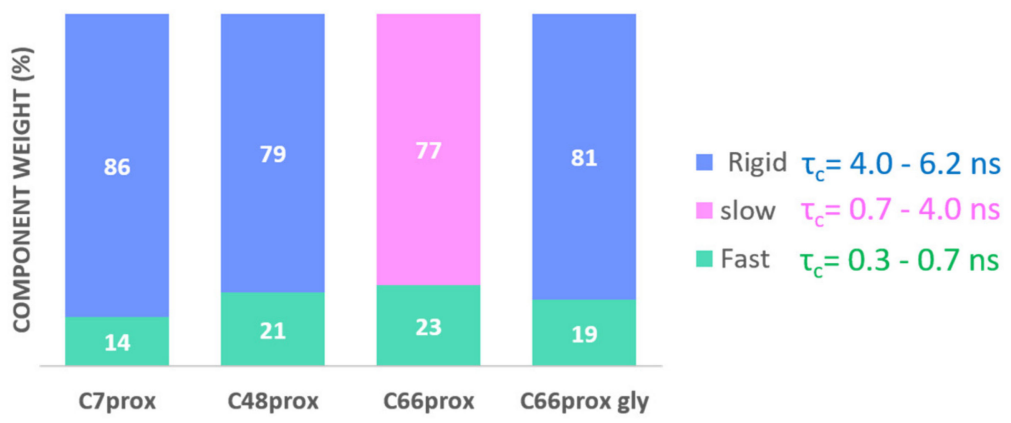

Figure 3. Conformational distribution of $H p$ UreG variants plotted in terms of the relative amount of the conformations obtained from simulation of EPR spectra. The different conformational ensembles are indicated using different colors and the relative correlation times are reported.

All these data experimentally confirm previously reported molecular dynamic simulations on $H p U r e G$, which suggested substantial rigidity in the protein regions involved in catalysis, justifying the residual catalytic activity of the isolated proteins, while evidencing the large dynamic flexibility for the protein portions involved in protein-protein interactions, which contain the residues in the conserved CPH motif [55].

To further investigate the structural dynamics of $H p U r e G$ in the apo-state, double electron-electron resonance (DEER) experiments were applied. DEER experiments allow to measure the dipolar coupling between spin pairs, yielding distance distribution between the coupled spins. Three double-Cys variants were constructed and labeled (C7prox $/ C 48^{\text {prox }}, \mathrm{C}^{\text {prox }} / \mathrm{C} 66^{\text {prox }}, \mathrm{C}^{\text {prox }} / \mathrm{C} 66^{\text {prox }}$ ) and their $\mathrm{CW}$ EPR spectra are reported in Supplementary Materials Figure S7. For all the DEER data shown in this section, the error on distance distribution results was calculated with the validation tool of DeerAnalysis (see Figure S8) [56]. DEER data of the C7prox $/ C 48^{\text {prox }}$ variant (Figure 4A) showed well-resolved distance distribution with 2 peaks centered at 2.4 and $3.5 \mathrm{~nm}$, while the one obtained for $\mathrm{C}^{\mathrm{proxyl}} / \mathrm{C}^{\mathrm{p}} 6^{\mathrm{proxyl}}$

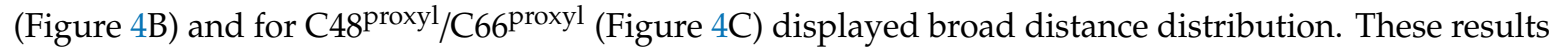
confirm the presence of considerable conformational heterogeneity in the protein sample, supporting the highly flexible behavior of $H p U r e G$, as already observed by previous NMR studies [20] and by the CW EPR data described above. 
A

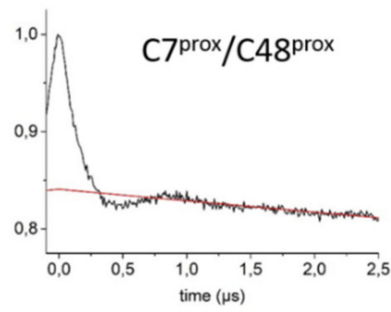

B
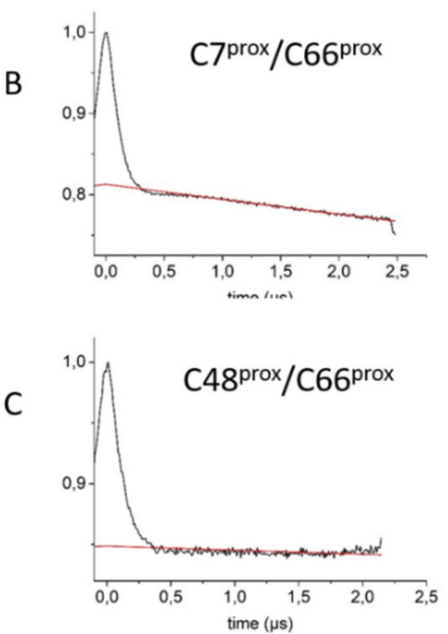
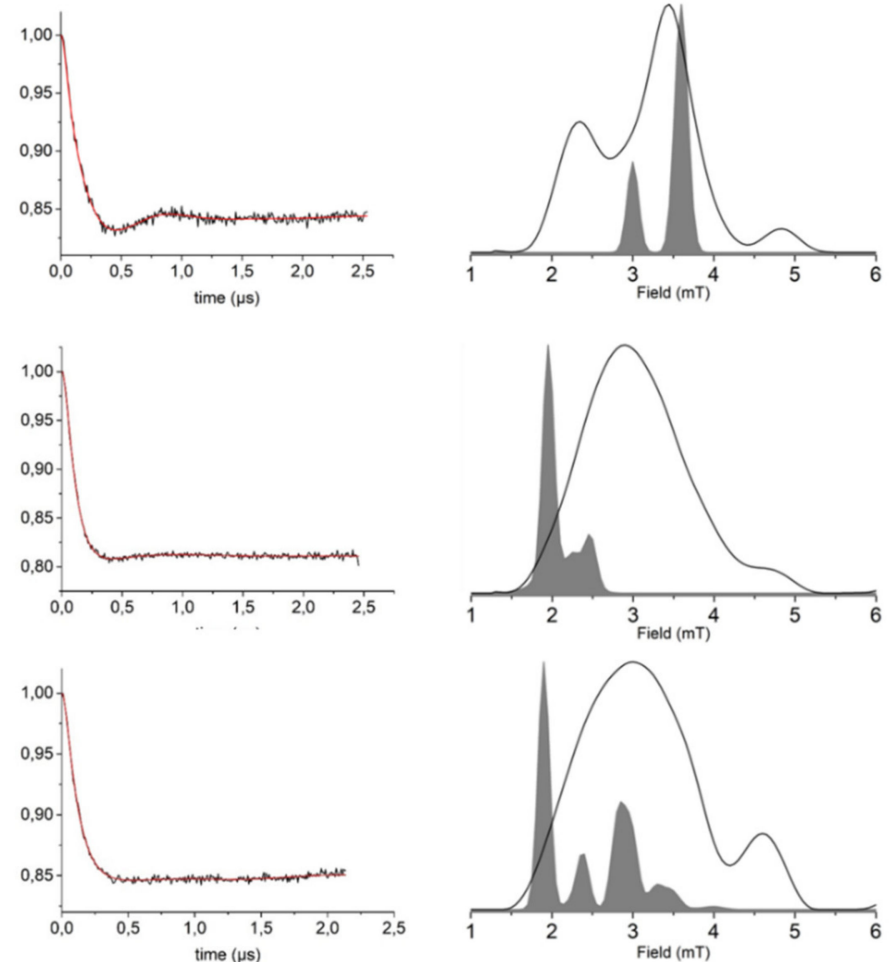

Figure 4. Inter-label distance distributions. (Left panel): experimental Q-band DEER traces recorded at

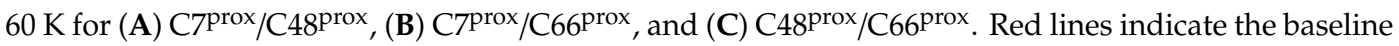
used for background correction. (Central panel): corrected Double Electron-Electron Resonance (DEER) traces (black) with superimposed fits derived from Tikhonov regularization (red). (Right panel): Tikhonov derived distance distributions obtained using DeerAnalysis (black) [56] superimposed with distance distributions calculated by MMM software (gray curves) [34].

In all cases, the average distance distributions measured by DEER span a broader range than those predicted by an MMM [34] analysis based on the HpUreG crystal structure (PDB: 4HI10) [21] and a library of rotamers for the MA-Proxyl spin label (Figure 4). This observation confirms that the experimental conditions used in the crystallization experiments (solutes and salts acting as precipitants) likely favored a more compact and rigid fold, as already shown for other biological systems [57], and that the protein structure observed in the crystal is different from the conformation that the protein assumes in solution.

\subsection{Ni(II) Ions and GTP Binding Produce Changes in the Structural Dynamics of Different Protein Regions}

Figure 5 shows the EPR spectra of the WTProx in the presence of either GTP or Ni(II), and in the presence of both cofactors. No significant spectral changes were detected after the addition of either GTP or Ni(II), while addition of both cofactors resulted in a clear change of the EPR line shape, corresponding to an increase of the broader components of the spectrum. This indicates that both ligands are necessary to induce structural changes in $\mathrm{H} p \mathrm{UreG}$.

To investigate the source of this spectral modifications, and in particular to sort out which of the three nitroxide labels bound to the protein contributes to the Ni(II) and GTP-driven line broadening, the experiment was repeated using the single-Cys variants of $H p$ UreG.

Addition of $\mathrm{Ni}(\mathrm{II})$ did not produce significant changes of the EPR line shapes for $\mathrm{C}^{\text {prox }}$ (Figure 6A) and $\mathrm{C}_{4} 8^{\text {prox }}$ (Figure 6B), while for the $\mathrm{C}_{6} 6^{\text {prox }}$ spectrum induced a line broadening (Figure $6 \mathrm{C}$ ), suggesting a reduction of the spin label mobility (Table 2 and Figure 3). Indeed, we observe a change in the weight of the two components (Table 2 and Figure 3), with the less flexible species becoming most abundant (from 44 to $66 \%$ ). 


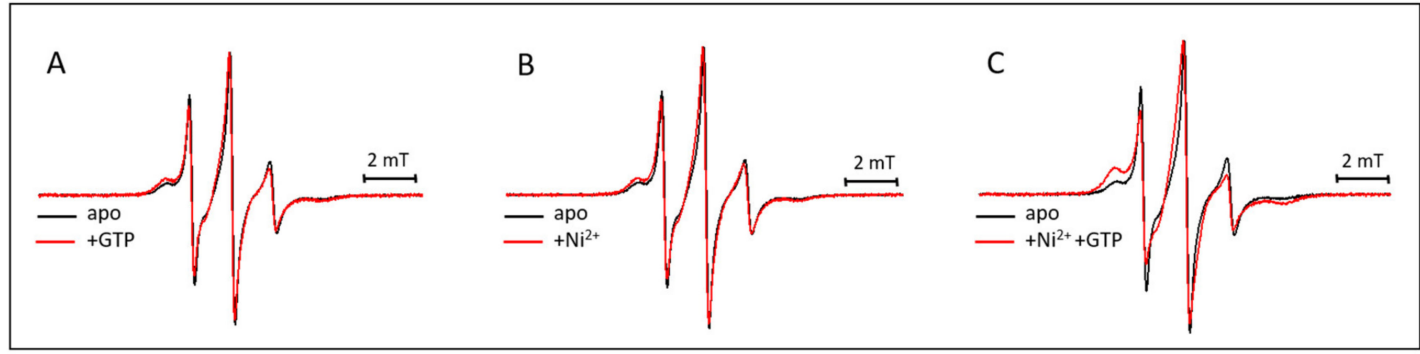

Figure 5. X-band CW EPR spectra of $50 \mu \mathrm{M} H p$ UreG labeled at the three naturally occurring Cys residues, recorded in solution and at room temperature. The apo-form spectra (black line) are compared to spectra recorded in presence of either $3 \mathrm{mM}$ GTP and/or $2.5 \mathrm{mM} \mathrm{Ni(II)} \mathrm{(red} \mathrm{line).}$
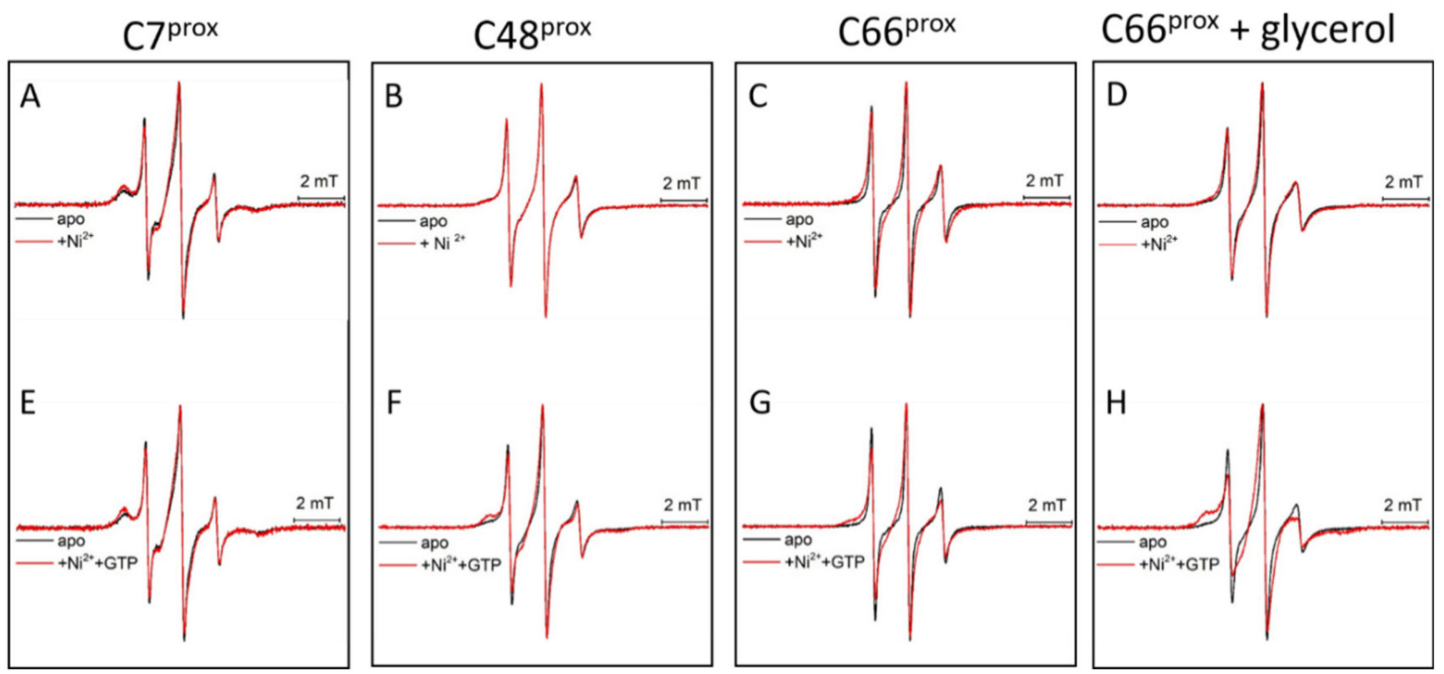

Figure 6. X-band CW EPR spectra of $H p U r e G$ variants at room temperature, in the absence and in the presence of glycerol. In the upper panels (A-D), the apo-form spectra are in black, those obtained in presence of $2.5 \mathrm{mM}$ of $\mathrm{NiSO}_{4}$ are in red. In the lower panels (E-H), the apo-form spectra (black line) are compared to spectra recorded in presence of either $3 \mathrm{mM} \mathrm{GTP}$ and/or $2.5 \mathrm{mM} \mathrm{Ni}$ (II) (red line).

Differently, no significant spectral changes were detected on all protein variants after the addition of GTP or GDP alone (Figures S9 and S10). We also tested the effect of $\mathrm{Mg}$ (II) to protein samples containing GTP or GDP. The addition of Mg(II) in equimolar concentration with respect to GTP, did not affect the spectral shape of the protein (Supplementary Materials Figure S11).

Concomitant addition of both $\mathrm{Ni}(\mathrm{II})$ and GTP did not significantly affect the spectrum of C7prox (Figure 6E), while it changed the line shape of $\mathrm{C} 48^{\text {prox }}$ (Figure 6F), with a conformational shift toward the "rigid" component, which increased from $63 \%$ to $79 \%$ (Table 2 and Figure 3). In the case of C66 $6^{\text {prox }}$, additional spectral changes were observed when GTP and Ni(II) bind to the protein; the $\tau_{\mathrm{c}}$ of both components increases, suggesting an induced structuration of this protein region (Table 2 and Supplementary Materials Section S2) or the dimerization of the protein upon both GTP and metal binding. These changes became more pronounced if the experiments were performed in the presence of glycerol, with a drastic change in the dynamics of the less flexible specie (Figure $6 \mathrm{H}$, red trace), whose $\tau_{\mathrm{c}}$ varies from $2.4 \mathrm{~ns}$ to $4.4 \mathrm{~ns}$ (Table 2 ). These results were confirmed for the $\mathrm{H} p \mathrm{UreG} \mathrm{C} 48^{\text {prox }} / \mathrm{C} 66^{\text {prox }}$ variant, which showed a similar behavior as found for C66 ${ }^{\text {prox }}$ in glycerol (Figure S12).

The observed spectral changes indicate that Ni(II) and GTP induce structural and dynamics modifications in the $\mathrm{Ni}$ (II)-binding region of the protein where $\mathrm{C} 66$ is located, and in the region around Helix 2, containing C48. This suggests the occurrence of an allosteric communication between the 
protein regions proximal to the $\mathrm{Ni}(\mathrm{II})$ and the GTP binding sites, whereas the region around the Cys7 residue is not affected by the presence of either Ni or GTP, or both.

To further investigate the structural effect of ligand binding on $\mathrm{H} p \mathrm{UreG}$ fold, DEER experiments would have been of great interest. However, the decrease in the $T_{m}$ (phase memory time) value (Figure S13A) associated with the field sweep (FS) intensity loss (Figure S13B) in the presence of $\mathrm{Ni}$ (II) prevented from obtaining properly exploitable DEER traces. Works are currently in progress to improve the quality of DEER experiments.

\section{Conclusions}

In this work, the structural dynamics of $H p U r e G$ was explored in the absence and in the presence of its physiological cofactors, $\mathrm{Ni}(\mathrm{II})$ and GTP. In solution, $\mathrm{H} p$ UreG fluctuates between different sub-states, this plasticity likely being a key factor to allow the protein to perform protein-protein and protein-metal ion interactions needed for $\mathrm{Ni}$ (II) ions delivery into the urease active site. ITC determined the conditions and the thermodynamic parameters of $\mathrm{Ni}(\mathrm{II})$ and GTP-driven protein dimerization, supported by light scattering data. SDSL-EPR demonstrated that the degree of structural flexibility changes along the protein backbone, with the region involved in GTP binding and the one involved in metal and protein interactions being more rigid and more flexible, respectively. EPR also revealed that concomitant addition of both $\mathrm{Ni}(\mathrm{II})$ and GTP is necessary for a structural transition in these two parts of the protein, located on opposite sides of the tertiary structure, with a shift of the conformational equilibrium towards a more structured state. Differently, addition of either the metal ions or the nucleotide produces only minor perturbations of the conformational equilibrium, indicating that both ligands are necessary to exert a significant conformational response. These observations suggest that binding of GTP in its pocket is propagated, along the protein backbone, to the metal binding site where $\mathrm{Ni}(\mathrm{II})$ is bound, and vice versa. The induced shift of the conformational ensemble of UreG likely regulates the protein function, possibly allowing the protein to shuttle $\mathrm{Ni}(\mathrm{II})$ ions from UreE to the $\mathrm{UreD}_{2}-\mathrm{UreF}_{2} \mathrm{complex}$ and, eventually, to urease.

Overall, the present work represents an important contribution for the characterization of the dynamics of UreG and its role in the network of the urease chaperone proteins. In the perspective to extend this original approach, involving SDSL-EPR spectroscopy, to the study of urease network directly inside bacterial cells, the results presented here provide important insights useful in the research on molecules with anti-bacterial activities to overcome anti-microbial resistance (AMR).

Supplementary Materials: The following can be found at http://www.mdpi.com/2218-273X/10/7/1062/s1: Supporting figures and tables as well as detailed descriptions of all experimental procedures, comprising EPR spectra simulations, site-directed mutagenesis, measurement of UreG GTPase activity, Size exclusion chromatography and light scattering data, are provided with the manuscript. Section S1: Supplementary figures (S1-S13), Section S2: CW spectra simulation with SimLabel program, Section S3: Methods summary.

Author Contributions: Conceptualization, B.Z. and E.M.; Data curation, G.G. and B.Z.; Formal analysis, E.E., B.G., S.C., V.B. and B.Z.; Funding acquisition, S.C. and E.M.; Investigation, A.P. and G.G.; Methodology, A.P.; Project administration, B.Z. and E.M.; Software, E.E.; Validation, B.G. and S.C.; Writing-original draft, S.C., V.B., B.Z. and E.M. All authors have read and agreed to the published version of the manuscript.

Funding: We acknowledge financial support from the "Agence Nationale de la Recherche" (ANR-18-CE11-0007-01) and from the "Conseil Régional Région Sud" (A.P. PhD Fellowship EJD-2018-2021). We also thank the COST Action MOBIEU (CA15126) for supporting this work via a Short-Term Scientific Mission to B.Z. and E.M. The University of Bologna contributed to this study through funds for basic research and for travel fellowships awarded to A.P. The "Consorzio Interuniversitario di Risonanze Magnetiche di Metallo-Proteine" (CIRMMP) is acknowledged for its financial support to B.Z. and S.C.

Acknowledgments: We thank K.C. Tamburrini for the labeling of $S p U r e G$ protein. We thank V. Fourmond for helpful discussion. We are grateful to the EPR facilities available at the national EPR network RENARD (IR 3443), and at the Aix-Marseille EPR center. We thank P. Mansuelle and R. Lebrun from Aix-Marseille Université and CNRS IMM (FR 3479), Plate-forme de Protéomique, 31 chemin Joseph Aiguier, 13402 Marseille, France, for mass spectrometry measurements and analyses.

Conflicts of Interest: The authors declare no conflict of interest. 


\section{References}

1. Laxminarayan, R.; Duse, A.; Wattal, C.; Zaidi, A.K.; Wertheim, H.F.; Sumpradit, N.; Vlieghe, E.; Hara, G.L.; Gould, I.M.; Goossens, H.; et al. Antibiotic resistance-the need for global solutions. Lancet Infect. Dis. 2013, 13, 1057-1098. [CrossRef]

2. Tornimbene, B.; Eremin, S.; Escher, M.; Griskeviciene, J.; Manglani, S.; Pessoa-Silva, C.L. WHO Global Antimicrobial Resistance Surveillance System early implementation 2016-17. Lancet Infect. Dis. 2018, 18, 241-242. [CrossRef]

3. Global priority list of antibiotic-resistant bacteria to guide research, discovery, and development of new antibiotics. Available online: https://www.who.int/medicines/publications/global-priority-list-antibioticresistant-bacteria/en/ (accessed on 27 February 2017).

4. Zambelli, B.; Musiani, F.; Benini, S.; Ciurli, S. Chemistry of Ni2+ in urease: Sensing, trafficking, and catalysis. Acc. Chem. Res. 2011, 44, 520-530. [CrossRef] [PubMed]

5. Beenken, K.E.; Dunman, P.M.; McAleese, F.; Macapagal, D.; Murphy, E.; Projan, S.J.; Blevins, J.S.; Smeltzer, M.S. Global gene expression in Staphylococcus aureus biofilms. J. Bacteriol. 2004, 186, 4665-4684. [CrossRef]

6. Zhou, C.; Bhinderwala, F.; Lehman, M.K.; Thomas, V.C.; Chaudhari, S.S.; Yamada, K.J.; Foster, K.W.; Powers, R.; Kielian, T.; Fey, P.D. Urease is an essential component of the acid response network of Staphylococcus aureus and is required for a persistent murine kidney infection. PLoS Pathog. 2019, 15, e1007538. [CrossRef]

7. Jones, B.D.; Lockatell, C.V.; Johnson, D.E.; Warren, J.W.; Mobley, H.L. Construction of a urease-negative mutant of Proteus mirabilis: Analysis of virulence in a mouse model of ascending urinary tract infection. Infect. Immun. 1990, 58, 1120-1123. [CrossRef]

8. Gatermann, S.; Marre, R. Cloning and expression of Staphylococcus saprophyticus urease gene sequences in Staphylococcus carnosus and contribution of the enzyme to virulence. Infect. Immun. 1989, 57, 2998-3002. [CrossRef]

9. Ligon, J.V.; Kenny, G.E. Virulence of ureaplasmal urease for mice. Infect. Immun. 1991, 59, 1170-1171. [CrossRef]

10. Zhou, F.; Yu, T.; Du, R.; Fan, G.; Liu, Y.; Liu, Z.; Xiang, J.; Wang, Y.; Song, B.; Gu, X.; et al. Clinical course and risk factors for mortality of adult inpatients with COVID-19 in Wuhan, China: A retrospective cohort study. Lancet 2020, 395, 1054-1062. [CrossRef]

11. Testerman, T.L.; Morris, J. Beyond the stomach: An updated view of Helicobacter pylori pathogenesis, diagnosis, and treatment. W. J. Gastroenterol. 2014, 20, 12781-12808. [CrossRef]

12. Eaton, K.A.; Brooks, C.L.; Morgan, D.R.; Krakowka, S. Essential role of urease in pathogenesis of gastritis induced by Helicobacter pylori in gnotobiotic piglets. Infect. Immun. 1991, 59, 2470-2475. [CrossRef]

13. D'Elios, M.M.; Czinn, S.J. Immunity, inflammation, and vaccines for Helicobacter pylori. Helicobacter 2014, 19, 19-26. [CrossRef]

14. Maroney, M.J.; Ciurli, S. Nonredox nickel enzymes. Chem. Rev. 2014, 114, 4206-4228. [CrossRef] [PubMed]

15. Mazzei, L.; Musiani, F.; Ciurli, S. CHAPTER 5 Urease. In The Biological Chemistry of Nickel; The Royal Society of Chemistry: London, UK, 2017; pp. 60-97.

16. Ha, N.-C.; Oh, S.-T.; Sung, J.Y.; Cha, K.A.; Lee, M.H.; Oh, B.-H. Supramolecular assembly and acid resistance of Helicobacter pylori urease. Nat. Struct. Biol. 2001, 8, 505-509. [CrossRef]

17. Tarsia, C.; Danielli, A.; Florini, F.; Cinelli, P.; Ciurli, S.; Zambelli, B. Targeting Helicobacter pylori urease activity and maturation: In-cell high-throughput approach for drug discovery. Biochim. Biophys. Acta Gen. Subj. 2018, 1862, 2245-2253. [CrossRef]

18. Bellucci, M.; Zambelli, B.; Musiani, F.; Turano, P.; Ciurli, S. Helicobacter pylori UreE, a urease accessory protein: Specific $\mathrm{Ni}(2+)$ - and $\mathrm{Zn}(2+)$-binding properties and interaction with its cognate UreG. Biochem. J. 2009, 422, 91-100. [CrossRef] [PubMed]

19. Musiani, F.; Gioia, D.; Masetti, M.; Falchi, F.; Cavalli, A.; Recanatini, M.; Ciurli, S. Protein Tunnels: The Case of Urease Accessory Proteins. J. Chem. Theory Computat. 2017, 13, 2322-2331. [CrossRef] [PubMed]

20. Zambelli, B.; Turano, P.; Musiani, F.; Neyroz, P.; Ciurli, S. Zn2+-linked dimerization of UreG from Helicobacter pylori, a chaperone involved in nickel trafficking and urease activation. Proteins Struct. Funct. Bioinform. 2009, 74, 222-239. [CrossRef] 
21. Fong, Y.H.; Wong, H.C.; Yuen, M.H.; Lau, P.H.; Chen, Y.W.; Wong, K.-B. Structure of UreG/UreF/UreH Complex Reveals How Urease Accessory Proteins Facilitate Maturation of Helicobacter pylori Urease. PLoS Biol. 2013, 11, e1001678. [CrossRef] [PubMed]

22. Yuen, M.H.; Fong, Y.H.; Nim, Y.S.; Lau, P.H.; Wong, K.-B. Structural insights into how GTP-dependent conformational changes in a metallochaperone UreG facilitate urease maturation. Proc. Natl. Acad. Sci. USA 2017, 114, E10890-E10898. [CrossRef] [PubMed]

23. Miraula, M.; Ciurli, S.; Zambelli, B. Intrinsic disorder and metal binding in UreG proteins from Archae hyperthermophiles: GTPase enzymes involved in the activation of $\mathrm{Ni}(\mathrm{II})$ dependent urease. J. Biol. Inorg. Chem. 2015, 20, 739-755. [CrossRef] [PubMed]

24. Real-Guerra, R.; Staniscuaski, F.; Zambelli, B.; Musiani, F.; Ciurli, S.; Carlini, C.R. Biochemical and structural studies on native and recombinant Glycine max UreG: A detailed characterization of a plant urease accessory protein. Plant Mol. Biol. 2012, 78, 461-475. [CrossRef] [PubMed]

25. Zambelli, B.; Musiani, F.; Savini, M.; Tucker, P.; Ciurli, S. Biochemical studies on Mycobacterium tuberculosis UreG and comparative modeling reveal structural and functional conservation among the bacterial UreG family. Biochemistry 2007, 46, 3171-3182. [CrossRef]

26. Zambelli, B.; Stola, M.; Musiani, F.; De Vriendt, K.; Samyn, B.; Devreese, B.; Van Beeumen, J.; Turano, P.; Dikiy, A.; Bryant, D.A.; et al. UreG, a chaperone in the urease assembly process, is an intrinsically unstructured GTPase that specifically binds Zn2+. J. Biol. Chem. 2005, 280, 4684-4695. [CrossRef] [PubMed]

27. Palombo, M.; Bonucci, A.; Etienne, E.; Ciurli, S.; Uversky, V.N.; Guigliarelli, B.; Belle, V.; Mileo, E.; Zambelli, B. The relationship between folding and activity in UreG, an intrinsically disordered enzyme. Sci. Rep. 2017, 7, 5977. [CrossRef]

28. D’Urzo, A.; Santambrogio, C.; Grandori, R.; Ciurli, S.; Zambelli, B. The conformational response to Zn(II) and $\mathrm{Ni}(\mathrm{II})$ binding of Sporosarcina pasteurii UreG, an intrinsically disordered GTPase. J. Biol. Inorg. Chem. 2014, 19, 1341-1354. [CrossRef]

29. Yang, X.; Li, H.; Lai, T.-P.; Sun, H. UreE-UreG Complex Facilitates Nickel Transfer and Preactivates GTPase of UreG in Helicobacter pylori. J. Biol. Chem. 2015, 290, 12474-12485. [CrossRef] [PubMed]

30. Merloni, A.; Dobrovolska, O.; Zambelli, B.; Agostini, F.; Bazzani, M.; Musiani, F.; Ciurli, S. Molecular landscape of the interaction between the urease accessory proteins UreE and UreG. Biochim. Biophys. Acta 2014, 1844, 1662-1674. [CrossRef]

31. Etienne, E.; Le Breton, N.; Martinho, M.; Mileo, E.; Belle, V. SimLabel: A graphical user interface to simulate continuous wave EPR spectra from site-directed spin labeling experiments. Magn. Reson. Chem. MRC 2017, 55, 714-719. [CrossRef]

32. Stoll, S.; Schweiger, A. EasySpin, a comprehensive software package for spectral simulation and analysis in EPR. J. Magn. Reason. 2006, 178, 42-55. [CrossRef]

33. Pannier, M.; Veit, S.; Godt, A.; Jeschke, G.; Spiess, H.W. Dead-Time Free Measurement of Dipole-Dipole Interactions between Electron Spins. J. Magn. Reason. 2000, 142, 331-340. [CrossRef] [PubMed]

34. Jeschke, G. MMM: A toolbox for integrative structure modeling. Protein Sci. Publ. Protein Soc. 2018, 27, 76-85. [CrossRef]

35. Jeschke, G. The contribution of modern EPR to structural biology. Emerg. Topics Life Sci. 2018. [CrossRef]

36. Bordignon, E. EPR Spectroscopy of Nitroxide Spin Probes. In eMagRes; Harris, R.K., Wasylishen, R.L., Eds.; John Wiley \& Sons, Ltd.: Chichester, UK, 2017.

37. Roser, P.; Schmidt, M.J.; Drescher, M.; Summerer, D. Site-directed spin labeling of proteins for distance measurements in vitro and in cells. Organ. Biomol. Chem. 2016, 14, 5468-5476. [CrossRef] [PubMed]

38. Potapov, A.; Yagi, H.; Huber, T.; Jergic, S.; Dixon, N.E.; Otting, G.; Goldfarb, D. Nanometer-Scale Distance Measurements in Proteins Using Gd3+ Spin Labeling. J. Am. Chem. Soc. 2010, 132, 9040-9048. [CrossRef]

39. Bonucci, A.; Ouari, O.; Guigliarelli, B.; Belle, V.; Mileo, E. In-Cell EPR: Progress towards Structural Studies Inside Cells. Chem. Bio. Chem. 2020, 21, 451-460. [CrossRef]

40. Hubbell, W.L.; McHaourab, H.S.; Altenbach, C.; Lietzow, M.A. Watching proteins move using site-directed spin labeling. Structure 1996, 4, 779-783. [CrossRef]

41. Hubbell, W.L.; Cafiso, D.S.; Altenbach, C. Identifying conformational changes with site-directed spin labeling. Nat. Struct. Biol. 2000, 7, 735-739. [CrossRef] [PubMed]

42. Hubbell, W.L.; Lopez, C.J.; Altenbach, C.; Yang, Z. Technological advances in site-directed spin labeling of proteins. Curr. Opin. Struct. Biol. 2013, 23, 725-733. [CrossRef] 
43. Le Breton, N.; Martinho, M.; Mileo, E.; Etienne, E.; Gerbaud, G.; Guigliarelli, B.; Belle, V. Exploring intrinsically disordered proteins using site-directed spin labeling electron paramagnetic resonance spectroscopy. Front. Mol. Biosci. 2015, 2, 21. [CrossRef]

44. Belle, V.; Rouger, S.; Costanzo, S.; Liquiere, E.; Strancar, J.; Guigliarelli, B.; Fournel, A.; Longhi, S. Mapping alpha-helical induced folding within the intrinsically disordered C-terminal domain of the measles virus nucleoprotein by site-directed spin-labeling EPR spectroscopy. Proteins 2008, 73, 973-988. [CrossRef] [PubMed]

45. Martinho, M.; Fournier, E.; Le Breton, N.; Mileo, E.; Belle, V. Nitroxide spin labels: Fabulous spy spins for biostructural EPR applications. In Electron Paramagnetic Resonance: Volume 26; The Royal Society of Chemistry: London, UK, 2019; Volume 26, pp. 66-88.

46. Jeschke, G. DEER distance measurements on proteins. Ann. Rev. Phys. Chem. 2012, 63, 419-446. [CrossRef] [PubMed]

47. Schiemann, O; Prisner, T.F. Long-range distance determinations in biomacromolecules by EPR spectroscopy. Quart. Rev. Biophys. 2007, 40,1-53. [CrossRef]

48. Schmidt, T.; Walti, M.A.; Baber, J.L.; Hustedt, E.J.; Clore, G.M. Long Distance Measurements up to 160 A in the GroEL Tetradecamer Using Q-Band DEER EPR Spectroscopy. Angew. Chem. Int. Ed. Engl. 2016, 55, 15905-15909. [CrossRef]

49. Pineiro, A.; Munoz, E.; Sabin, J.; Costas, M.; Bastos, M.; Velazquez-Campoy, A.; Garrido, P.F.; Dumas, P.; Ennifar, E.; Garcia-Rio, L.; et al. AFFINImeter: A software to analyze molecular recognition processes from experimental data. Anal. Biochem. 2019, 577, 117-134. [CrossRef] [PubMed]

50. Zambelli, B.; Bellucci, M.; Danielli, A.; Scarlato, V.; Ciurli, S. The Ni2+ binding properties of Helicobacter pylori NikR. Chem. Commun. 2007, 21, 3649-3651. [CrossRef]

51. López, C.J.; Fleissner, M.R.; Guo, Z.; Kusnetzow, A.K.; Hubbell, W.L. Osmolyte perturbation reveals conformational equilibria in spin-labeled proteins. Protein Sci. Publ. Protein Soc. 2009, 18, 1637-1652. [CrossRef]

52. Flores Jiménez, R.H.; Do Cao, M.A.; Kim, M.; Cafiso, D.S. Osmolytes modulate conformational exchange in solvent-exposed regions of membrane proteins. Protein Sci. Publ. Protein Soc. 2010, 19, 269-278. [CrossRef]

53. Bolen, D.W. Effects of naturally occurring osmolytes on protein stability and solubility: Issues important in protein crystallization. Methods 2004, 34, 312-322. [CrossRef]

54. Mileo, E.; Lorenzi, M.; Erales, J.; Lignon, S.; Puppo, C.; Le Breton, N.; Etienne, E.; Marque, S.R.; Guigliarelli, B.; Gontero, B.; et al. Dynamics of the intrinsically disordered protein CP12 in its association with GAPDH in the green alga Chlamydomonas reinhardtii: A fuzzy complex. Mol. Biosyst. 2013, 9, 2869-2876. [CrossRef]

55. Musiani, F.; Ippoliti, E.; Micheletti, C.; Carloni, P.; Ciurli, S. Conformational fluctuations of UreG, an intrinsically disordered enzyme. Biochemistry 2013, 52, 2949-2954. [CrossRef] [PubMed]

56. Jeschke, G.; Chechik, V.; Ionita, P.; Godt, A.; Zimmermann, H.; Banham, J.E.; Timmel, C.R.; Hilger, D.; Jung, H. DeerAnalysis2006-A Comprehensive Software Package for Analyzing Pulsed ELDOR Data. Appl. Magn. Reson. 2006, 30, 473-498. [CrossRef]

57. Sarver, J.L.; Zhang, M.; Liu, L.; Nyenhuis, D.; Cafiso, D.S. A Dynamic Protein-Protein Coupling between the TonB-Dependent Transporter FhuA and TonB. Biochemistry 2018, 57, 1045-1053. [CrossRef] [PubMed]

(C) 2020 by the authors. Licensee MDPI, Basel, Switzerland. This article is an open access article distributed under the terms and conditions of the Creative Commons Attribution (CC BY) license (http://creativecommons.org/licenses/by/4.0/). 